\title{
Delamination Identification of Composites using Normalized Modal Curvature and Image Processing
}

\author{
S Sanyasi Naidu ${ }^{1}$ \\ ${ }^{1}$ Assistant Professor, \\ Department of Mechanical Engineering, \\ MVGR College of Engineering.
}

\author{
Ch. Ratnam ${ }^{2}$ \\ ${ }^{2}$ Professor, \\ Department of Mechanical Engineering, \\ AU College of Engineering (A), Visakhapatnam.
}

\author{
$\mathrm{G} \mathrm{Rambabu}^{3}$ \\ ${ }^{3}$ Assistant Professor, \\ Department of Mechanical Engineering, \\ AU College of Engineering(A), India.
}

\begin{abstract}
Delamination in FRP composites causes a considerable reduction in the transverse load carrying capacity, which is a major apprehension to the aerospace and automotive industries. Because of comparatively low cost and the flexibility of measurement. Modal analysis based damage identification in the composite materials is usefully employed in structural health monitoring. Using normalized modal curvature the delamination location detection is discussed in this paper. For the intact and delaminated composite, numerical modal analysis is performed using ANSYS-ACP. Modal parameters (frequency and mode shape) are extracted from the simulated composite plate. Modal curvature at each node is calculated by double differentiation of mode shape deformation. Damage Index (DI) is formulated using the modal curvature of intact and delaminated composite plates. Analyzing DI at each node of the plate region delamination is identified. Damage Index based delamination identification validated with Image Processing technique. The proposed approaches successfully identify the delamination position and size of the composites.
\end{abstract}

Key Words: Delamination, Finite Element Modal Analysis, Modal Curvature, and Image Processing

\section{INTRODUCTION}

Laminated composites suppliant traditional metals in the marine, automotive, construction and aerospace industries in the present time. The composite material's most important reward is relatively low weight, resistance to corrosion, and high strength to weight ratio. Nevertheless, these composites are susceptible to delamination and therefore necessitate early detection of the defect before it reaches critical damage. The discovery of cost-efficient and reliable damage is crucial to the use of composite resources. To avoid the sudden breakage down, monitoring of such structure for safety is extremely necessary.

Delamination is the most common mode of failure of composite failure. Debonding between the neighboring layers is known as delamination at a particular region of the multilayered composite plate. It reduces laminated composite compressive strength. It happens inside of the composite layers, so the presence of delamination in the multilayered composites is difficult to identify. Therefore, the delamination forecast in composite plates is required during the service life.

Material characterization is one of the important aspects in the design of mechanical components. In general, the elastic constants are determined by destructive tests like tensile, bending, and shearing, etc., but we can also determine the elastic constants by nondestructive tests. Elastic constants are determined by vibration testing [1,2], approximate mathematical equations are formulated between the natural frequencies and elastic constants. The wave decomposition technique [3] is used to compute the whole set of 21elasticstiff nesses of the composites by measuring the ultrasonic phase velocity through the composite material. Quasi-S and quasi-P [4] waves are incidents with a variety of angles through the material.

Damage identification through numerical analysis, modeling of composites with their damages is played an important role. Composite plates modeled as separate layers and delamination is implemented using 9 nodded quadrilateral MITC9 element [5], which is devoid of membrane locking and shear locking. Delamination is also implemented as a separation of $0.02 \mathrm{~mm}$ between the adjust layers [6], and Virtual spring elements [7] are adopted in the area of delamination with less stiffness than other regions.

The modal analysis based singularity (damage) recognition is an efficient method because of its ease of accomplishment, acquire the global and the local information of the composite structures. Essential efforts are previously committed to developing damage identification algorithms using a vibration based approach. The parameters used for damage identification using modal analysis are fundamental frequencies, damping ratios, mode 
shapes, modal curvature, and modal strain energy. For firstlevel structural health monitoring (SHM) natural frequencies $[8,10]$ used because of global nature. Mode shape [9-12] information and its modified form with special algorithms are used to find the second level of SHM, the position of the significant damage in structures. Modal curvatures and modal strain energy are more sensitive at local regions than mode shapes and natural frequencies. Modal curvature [12-20] and its modified forms like change in curvatures, normalized curvatures, modal assurance criteria are used to identify the small-size damages.

In image processing perform several of operations on image to enhance the image and extract some characteristics from it. It is one type of signal processing in which the input and output are images. In recent years, Image processing is one of the fast growing technology. The research work related to image processing covers to all engineering specializations. This method is useful to identify the external damages like road damages [21,22], damages on the walls of the tall buildings[23], damages on the bodies of airplanes, naval ships. It is very much useful in the automation of Structural Health Monitoring.

This effort aims to study the characteristics of modal curvature (MC), to detect the delamination center in the composite plates. First, Modal curvature is calculate using mode deformation data of the intact and delaminated plates. The Second, Damage index (DI) is estimated at each node using normalized modal curvatures. Delamination location and quantification are done using the DI matrix of the composite plate. Delamination is also evaluated using image processing of delaminated composite plates.

\section{THEORY}

The second-order derivative of mode shape $\mathrm{w}^{\mathrm{w}(x, y)}$ of a composite plate is considered as the modal curvature.

$\kappa=K_{x x}+K_{y y}=\frac{\partial^{2} w(x, y)}{\partial x^{2}}+\frac{\partial^{2} w(x, y)}{\partial y^{2}}$

Where $\kappa, \quad \kappa_{x x}$ and $\kappa_{y y}$ are modal curvatures , modal curvature along $\mathrm{X}$-axis and modal curvature along $\mathrm{Y}$ axis respectively.

\subsection{NORMALIZED MODAL CURVATURE. :}

The damage factor referred to an as absolute difference of the modal curvatures of the intact with delaminated composite plates. At delamination location, local modal curvature is increased due to the reduction of stiffness of composite plates[12].

Modal Curvature is estimated from mode shape obtained from the finite element modal analysis by central difference approximation. The modal curvatures in the direction of $\mathrm{X}$ axis and Y-axis are obtained mathematically as [12]:

$$
\begin{gathered}
\kappa_{\mathrm{xx}}=\frac{\mathrm{w}_{(\mathrm{i}-1) \mathrm{j}}-2 \mathrm{w}_{\mathrm{i}, \mathrm{j}}+\mathrm{w}_{(\mathrm{i}+1) \mathrm{j}}}{\mathrm{h}^{2}} \\
\kappa_{\mathrm{yy}}=\frac{\mathrm{w}_{\mathrm{i}_{\imath}(\mathrm{j}-1)}-2 \mathrm{w}_{\mathrm{i}, \mathrm{j}}+\mathrm{w}_{\mathrm{i}_{\imath}(\mathrm{j}+1)}}{\mathrm{h}^{2}} \\
\kappa=\kappa_{x x}+\kappa_{y y}
\end{gathered}
$$

Where $\mathrm{i}$ and $\mathrm{j}$ are row and column, ${ }^{w_{i j} j}$ is mode shape value of ith row and jth column composite plate.

The change in modal curvature (CMC) is an absolute difference of modal curvatures of delaminated and intact composite plates:

$\Delta \kappa_{i, j}=\kappa_{i, j}^{(d)}-\kappa_{i, j}^{(u)}$

The CMC is calculated through equation (5), at each grid node of the composite plate and normalized CMC at each node to the same range by the following equation.

$$
\Delta \kappa_{i, j}=1+\frac{\Delta \kappa_{i, j}}{\max \left(\Delta \kappa_{i, j}\right)-\min \left(\Delta \kappa_{i, j}\right)}
$$

This normalized CMC is considered as Damage Index (DI) at each node.

\section{MODAL ANALYSIS OF COMPOSITES:}

\subsection{NUMERICAL MODAL ANALYSIS:}

The Glass/epoxy composite plate $(120 \times 120 \times 6.8)$ by stacking sequence $\left[0 \% / 90^{\circ} / 0^{\circ} / 90^{\circ}\right] \mathrm{s}$ was consider for numerical analysis.20x20 $\mathrm{mm}^{2}$ delamination area is consider at centre, right and North East positions. The elastic constants of the composites for FEM simulation are $\mathrm{E}_{1}=44.63 \mathrm{GPa}, \mathrm{E}_{2}=8.46 \mathrm{GPa}, \mathrm{E}_{3}=8.46 \mathrm{GPa}, \mathrm{v}_{12}=0.26, \mathrm{v}_{13}$ $=0.26, v_{23}=0.21, \mathrm{G}_{12}=3.23 \mathrm{GPa}, \mathrm{G}_{13}=3.23 \mathrm{GPa}, \mathrm{G}_{23}$ $=4.32 \mathrm{GPa}$, and $\rho=1832 \mathrm{~kg} / \mathrm{m}^{3}$.

ANSYS- ACP (pre) software is used of modeling of the composite plate. Delamination is incorporated in the interface layer as an open area during the modeling of composites. The numerical modal investigation is done on the intact and delaminated composite plates to take out the mode shapes and natural frequencies. Modal curvatures to the first mode are calculated using the first mode shape. 


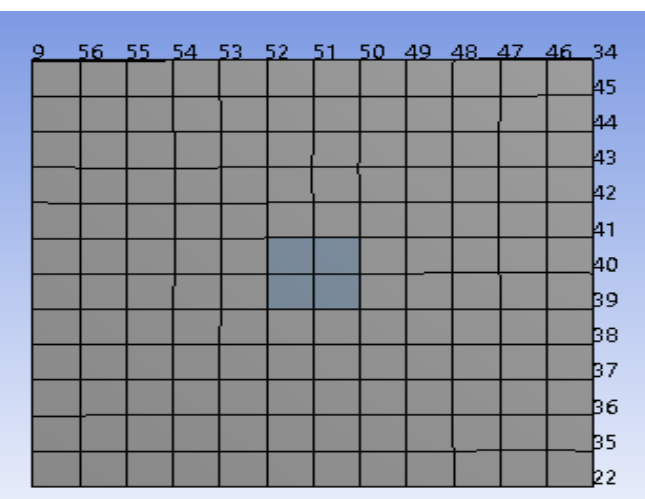

Fig.1 Meshed model of delaminated plate
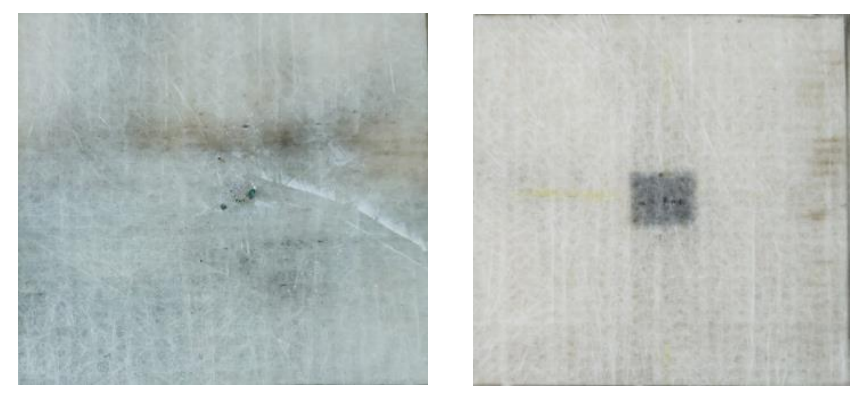

Fig .3 Specimens of Intact and delamination at three positions

\subsection{IMAGE PROCESSING:}

In image processing perform several operations on image to enhance the image and extract some characteristics from it. It in one type of signal processing in which the
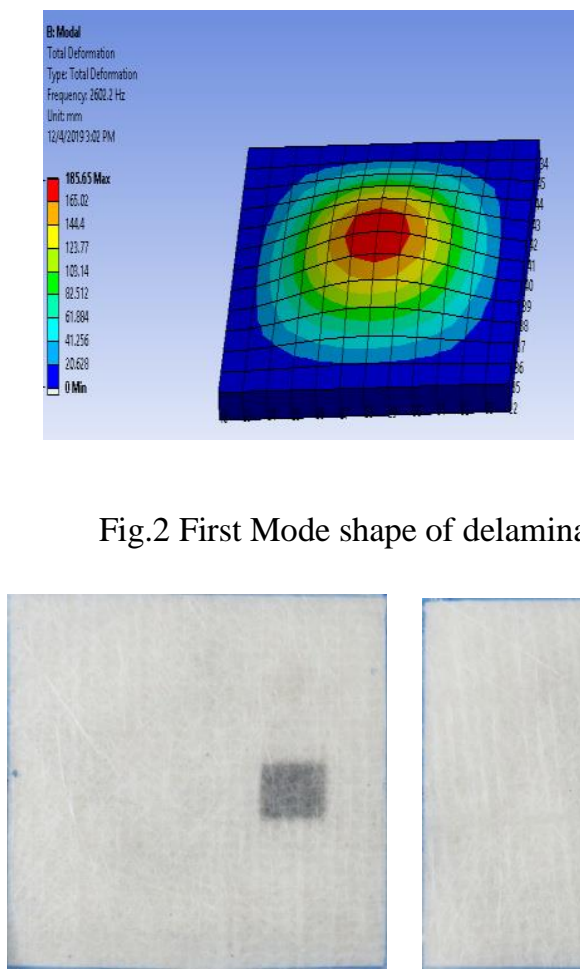

Fig.2 First Mode shape of delaminated plate

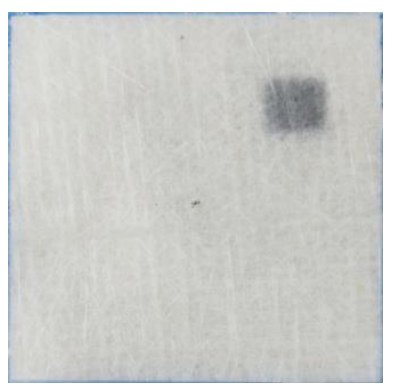

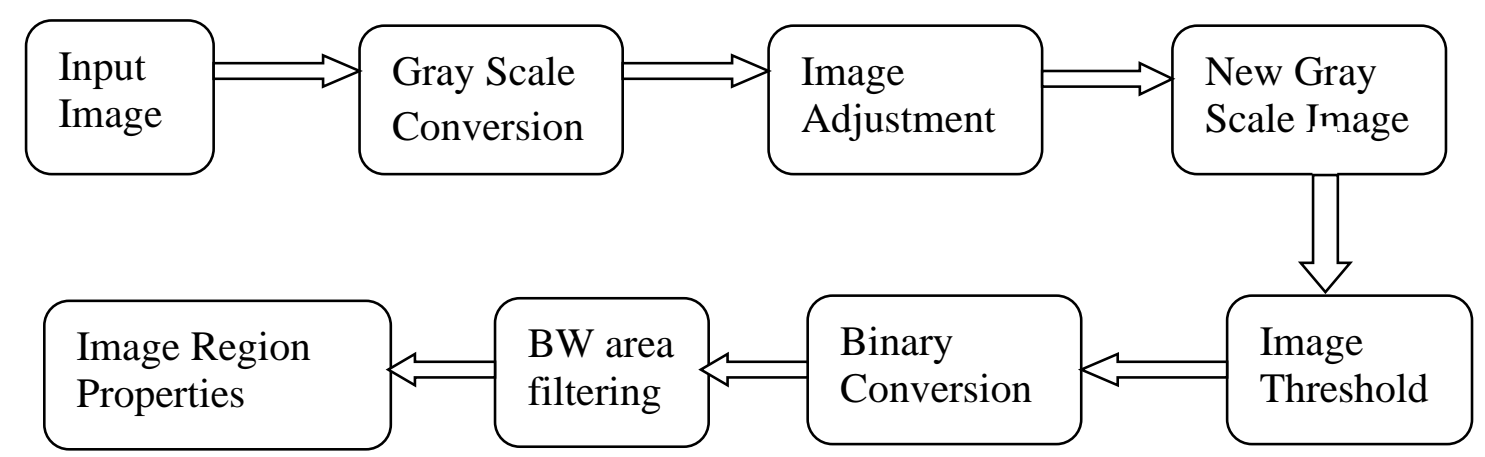

Fig.4. Flow Chart of Image Processing

\subsubsection{PRE-PROCESSING}

In image processing, image from camera consists of errors related to surface stains and fibers of the composites. Using suitable mathematical models like definite or statistical models the errors are corrected. Pre processing includes some operations of the input image to remove the unnecessary data from the image. The objective of the pre processing is to reduce the executing time. Colored image consists of three planes (RBG). processing of colored image is somewhat complex and time taking, so it is covert into grayscale image. Enhanced techniques are used to remove noise, blurriness and uneven lighting. input and output are images. The following flow chart indicates the process to obtain the geometric center an area of delamination of composite plates. 
The following procedure is adopted in this paper.

To suppress the noise in the image, which is not required for delamination identification, the grayscale image is converted into binary image. The binary image representation is simple in the forms of zeros and ones. The threshold is adjusted such that the image does not lose its characteristics of delamination during conversion from grayscale to binary. The morphological functions are used to reduce the noise in the image by removing the small objects. which gives another binary image. Using binary area filtering and region properties, the area of delamination and center are evaluated.

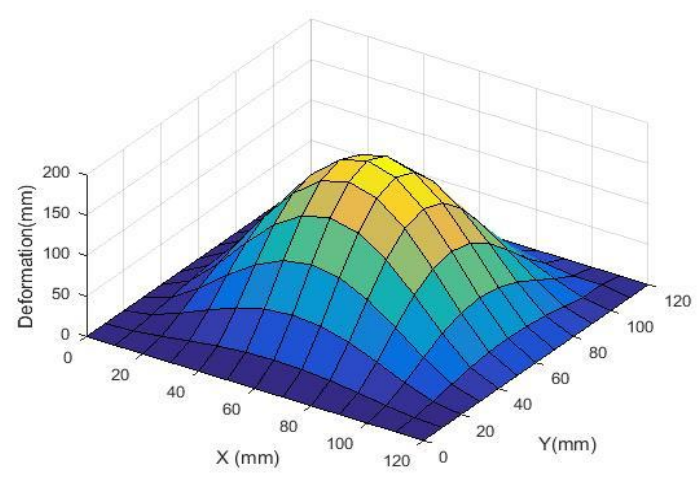

a)

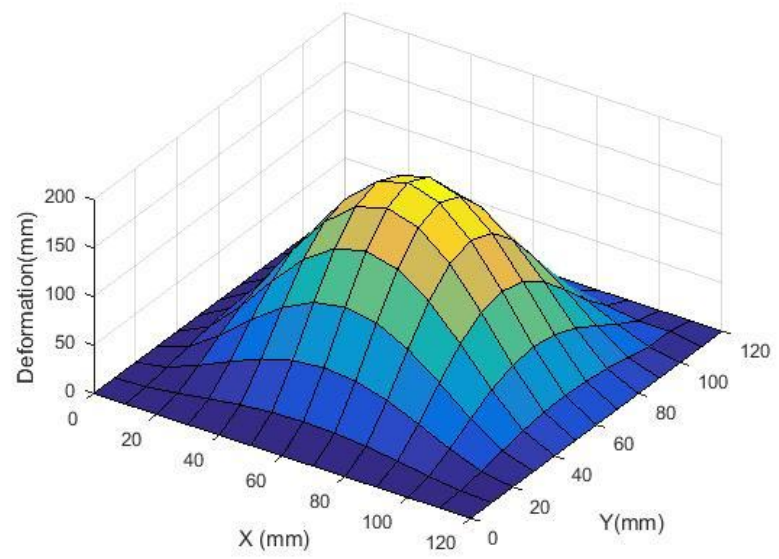

c)

\section{RESULTS ALONG WITH DISCUSSIONS}

\subsection{Numerical Results:}

Numerical modal analysis is performed on the eight-layer composite plate with stacking sequence [0/90/0/90]s using ANSYS -ACP(Pre) software for intact and delaminated plates with three delamination positions at the center, right and $\mathrm{NE}$ of $20 \times 20 \mathrm{~mm} 2$ delamination area. The fixed boundary condition is applied for all the edges of the plate in numerical analysis. The first frequency and mode shape are extracted for the intact and delaminated composites by the numerical modal analysis.

The mode shape deformations of the composites are revealed in figure 5. All mode shapes seem to be similar, there no singularity in mode shapes of composite plates, so we can't identify the delamination location

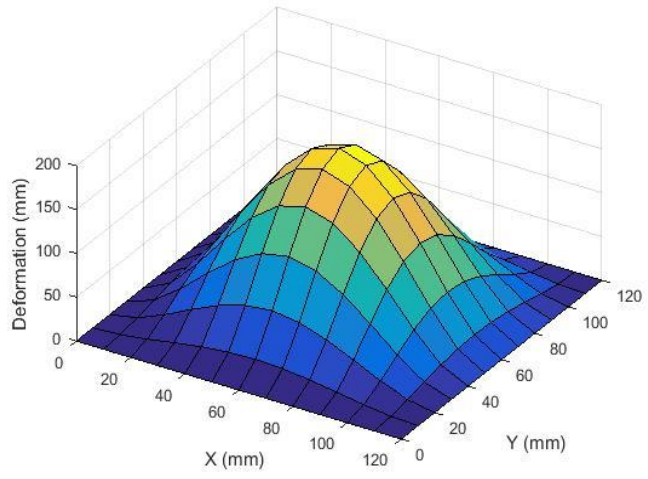

b)

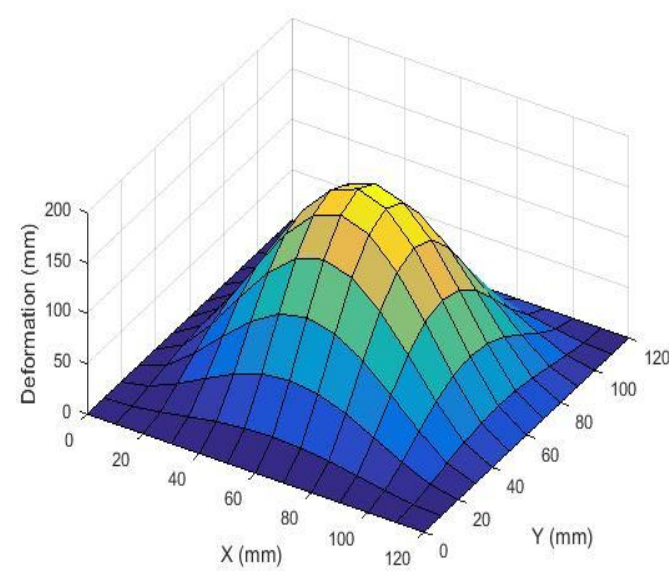

d)

Fig.5.Mode Shapes of composite plates, a) Intact b) Delamination at Center c) Delamination at Right-sided d) Delamination at NE Corner

Modal curvatures of the intact and three delaminated composites are calculated using mathematical equations (2), (3) and (4). The modal curvature plots of intact and three delaminated composites are shown in figure 6 . There is a small deviation of the surface at the delamination location, but this deviation is dominated as a result of the global tendency of the modal curvature surface, so this singularity is not sufficient to identify the delamination positions of the composite plates 


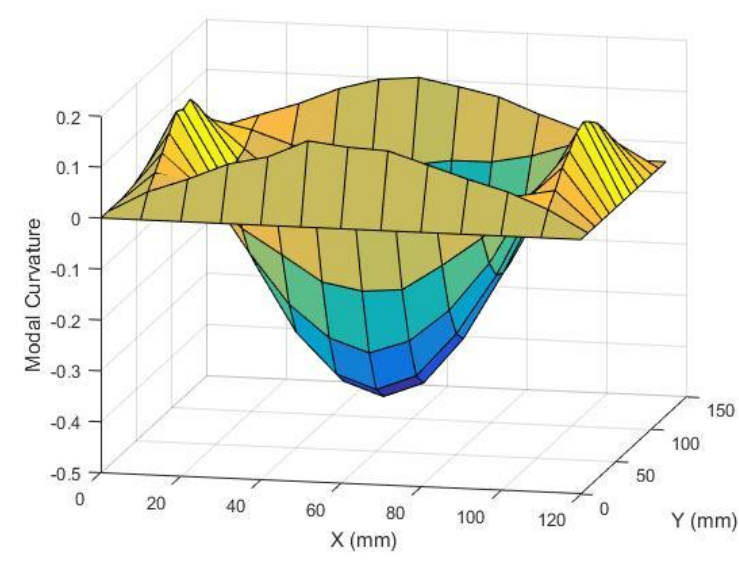

a)

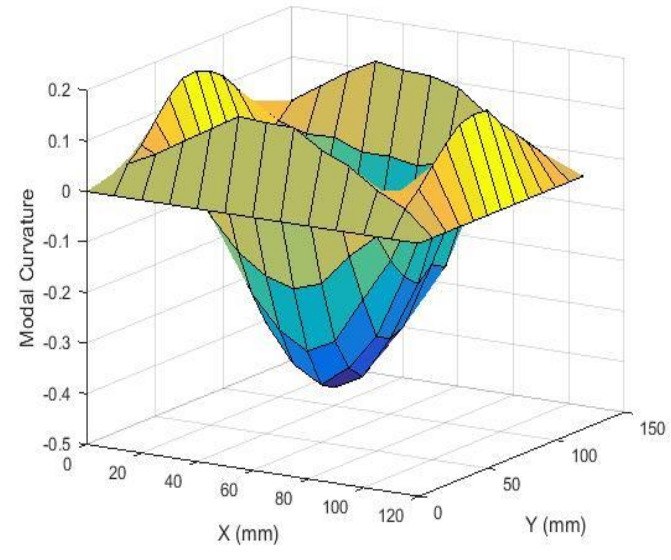

c)

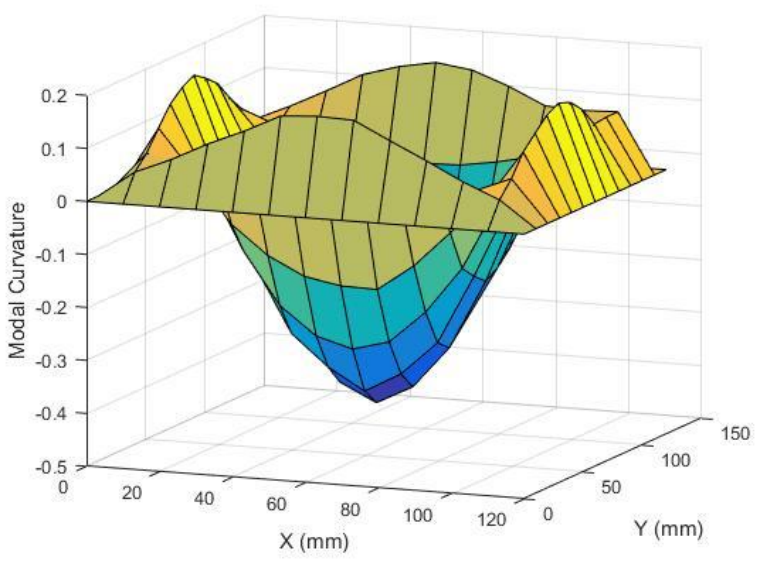

b)

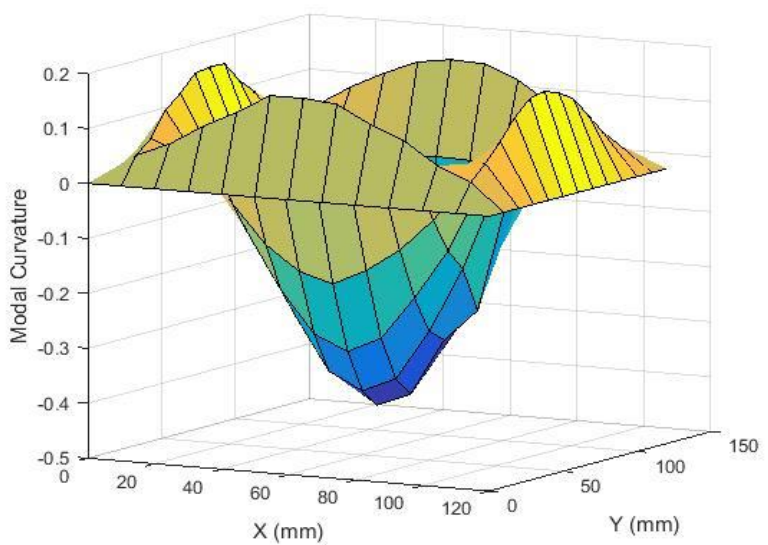

d)

Fig.6.Modal Curvatures of composite plate, a) intact b) Delamination at Center c) Delamination at Right side d) Delamination at NE Corner

Mode shapes and Modal Curvatures of the delaminated composite plates are not sufficient to identify the delamination locations. The damage indexing method is developed by means of the absolute difference of modal curvatures of the intact with delaminated composite plates. Using mathematical equations (5) and (6) damage index of delaminated plates at each node is calculated.The damage indices and plan view of Normalized modal curvature of composite plate's delamination at the center, right and northeast positions respectively shown in the following figures 7 to 9 . The larger values of damage indices indicate the delamination position of the composite plate.

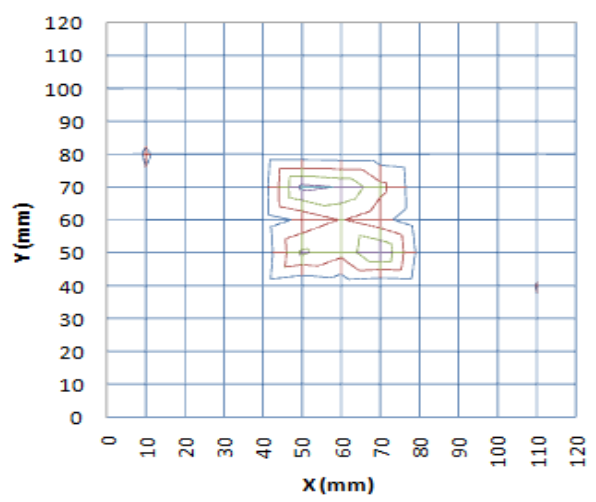

b)

Fig.7. Delamination at center, a) Damage Index, b) Plan form of Normalized Modal Curvatures 

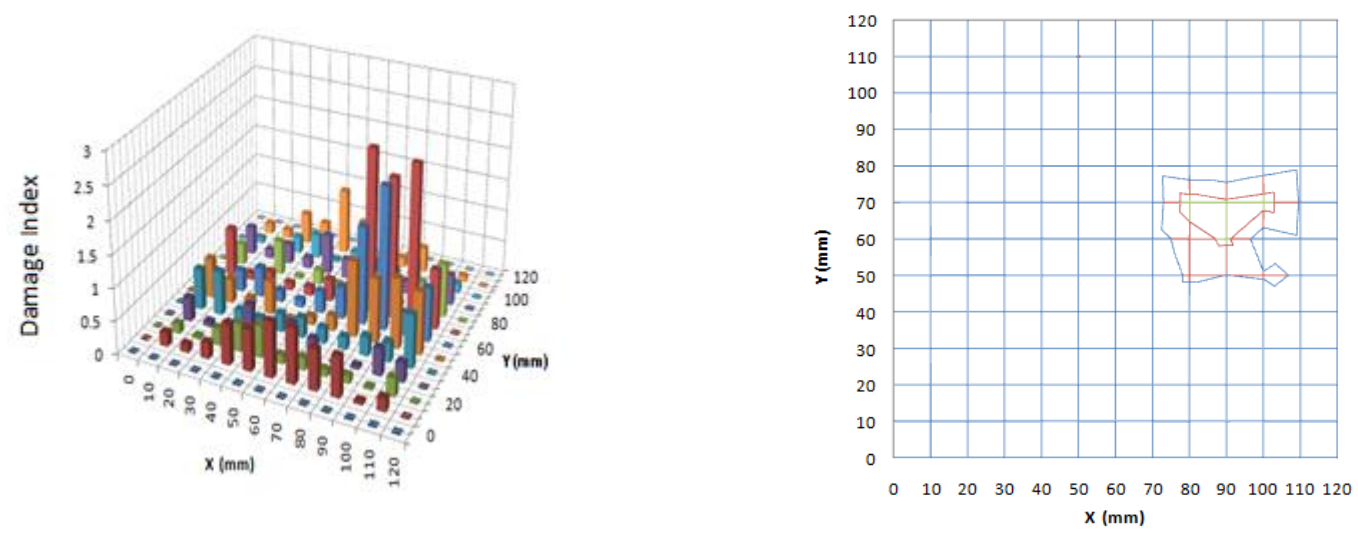

Fig.8. Delamination at Right, a) Damage Index, b) Plan form Normalized Modal Curvatures
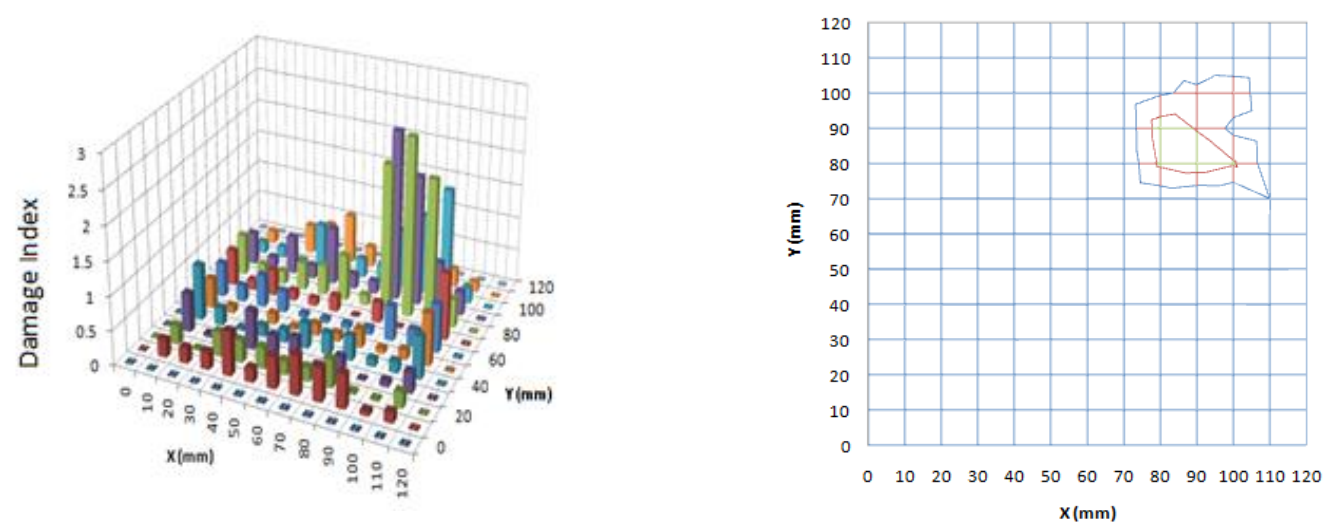

Fig.9. Delamination at NE, a) Damage Index, b) Plan form Normalized Modal Curvatures

Using the Plan form of the normalized modal curvatures of composite plates, delamination centers are estimated and shown in table 1.

Table:1Actual, and Numerical Delamination centers of composite plates

\begin{tabular}{|c|c|c|c|c|}
\hline & \multicolumn{4}{|c|}{ Delamination Position } \\
\hline S.No. & \multicolumn{2}{|c|}{ Actual } & \multicolumn{2}{c|}{ Numerical Method } \\
\hline & $\mathrm{X}(\mathrm{mm})$ & $\mathrm{Y}(\mathrm{mm})$ & $\mathrm{X}(\mathrm{mm})$ & $\mathrm{Y}(\mathrm{mm})$ \\
\hline 1 & 60 & 60 & 60 & 60 \\
\hline 2 & 90 & 60 & 90 & $60-70$ \\
\hline 3 & 90 & 90 & $80-90$ & 90 \\
\hline
\end{tabular}

\subsection{IMAGE PROCESSING RESULTS:}

The images of the three delaminated composites are taken from constant height using 20 megapixel camera. The sequence of operations is shown in figure 4 . for the processing of the input images. MAT Lab software is used

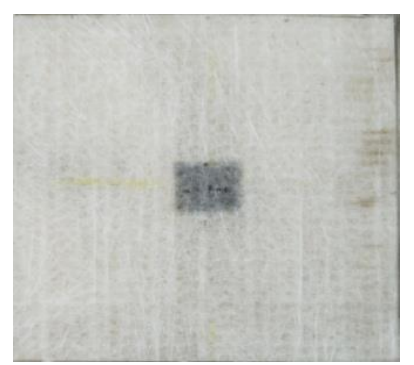

Fig.10. Delamination at center, a) Original image, b) Processed Image transparent of composites.

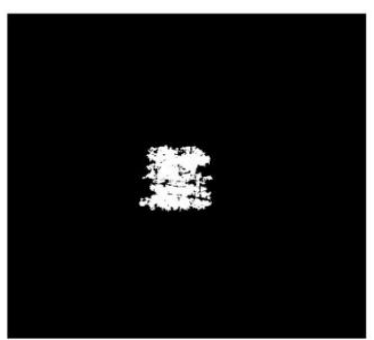

for the image processing, the processed images are shown in figures 10,11, and 12. The white color region indicate the delamination area, still, noise in occurs, which is due semi- 

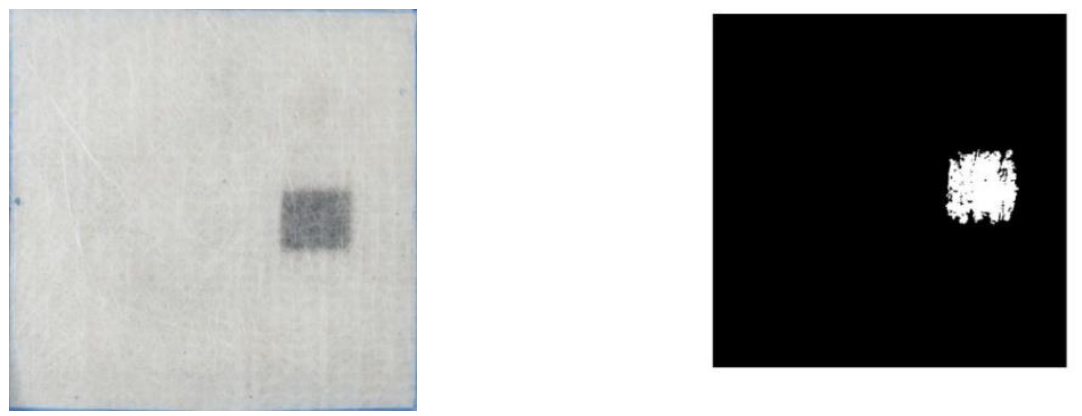

Fig.11. Delamination at right side, a) Original image, b) Processed Image
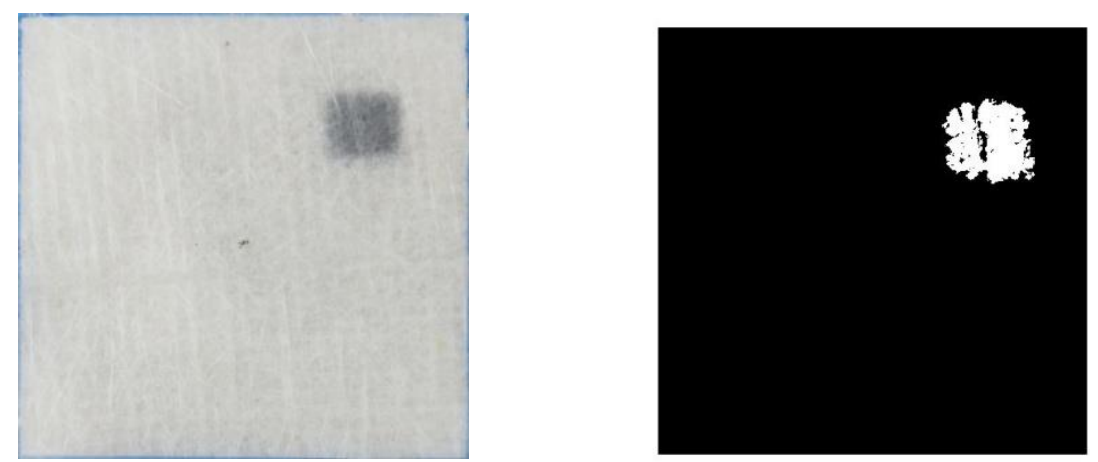

Fig.12. Delamination at NE corner, a) Original image, b) Processed Image

Using region properties the geometric center and area of delamination of processed images are estimated in pixels, by selecting proper conversion factors which are converted into $\mathrm{mm}$.

Table: 2 The Actual and Image Processed Delamination centers of composite plates

\begin{tabular}{|c|c|c|c|c|}
\hline & \multicolumn{4}{|c|}{ Delamination Position } \\
\hline S.No. & \multicolumn{2}{|c|}{ Actual } & \multicolumn{2}{c|}{ Image Processing } \\
\hline & $\mathrm{X}(\mathrm{mm})$ & $\mathrm{Y}(\mathrm{mm})$ & $\mathrm{X}(\mathrm{mm})$ & $\mathrm{Y}(\mathrm{mm})$ \\
\hline 1 & 60 & 60 & 56.7290 & 61.0941 \\
\hline 2 & 90 & 60 & 88.4459 & 56.9119 \\
\hline 3 & 90 & 90 & 92.6875 & 87.9555 \\
\hline
\end{tabular}

Table:3 Comparison of delamination areas of actual and image processed

\begin{tabular}{|c|c|c|c|}
\hline S.No. & \multicolumn{2}{|c|}{ Delamination Area $\left(\mathrm{mm}^{2}\right)$} & \multirow{2}{*}{ Percentage of Error } \\
\hline & Actual & Image Processing & 7.64 \\
\hline 2 & 400 & 369.4119 & 4.76 \\
\hline 3 & 400 & 419.0220 & 2.79 \\
\hline
\end{tabular}

\section{CONCLUSIONS}

This research work studies the delamination position identification of composite laminates using normalized modal curvatures. Normalized modal curvatures are formulated using modal curvatures of the undamaged(intact) and delaminated composite plates. The composite plates with three delamination positions are analyzed by numerical modal analysis and image processing. The results from the numerical analysis and image processing the consequent conclusions are drawn and discussed as follows:

* Modal Curvature is more significant parameter than mode shape to delamination identification.
* The proposed Normalized modal curvature-based DI index method successfully identifies the Delamination location.

* The Image processing method is also finding the location and area of the delamination, which is used to validate the results of DI method.

* The area of delamination in DI method is more than the image processing, because the stiffness effect zone is more than delamination area, modal curvature is influenced by stiffness.

* Both the proposed methods are also used to find the multiple delaminations (damages) of composite plates. 


\section{REFERENCES}

[1] Shunfah wang, Chang, Linchang Kung. Determination of Elastic Constants of transversely Isotropic Materials by Combining Vibration Testing and Numerical method. Polymer composites 2001; Vol.22,No.2: pp. 242-249.

[2] H.D. Lafa. Experimental Determination of Elastic Constants of Composite Materials Using Vibration Properties. Journal of Engineering and Development 2013;Vol.17:pp. 22-30.

[3] M.Marko, D.R.Schmitt. Determination of the complete elastic stiffnesses from ultrasonic phase velocity measurements. Journal of Geophysical Research 2016; Vol.108: pp.6- 11.

[4] A..Every, W.Sachse. Determination of the elastic constants of anisotropic solids from acoustic wave group velocity measurements. Physical Review B 2012; Vol,42: pp.8196-8205.

[5] S.K. Kumar, Cinifra M., E.Carrera.,R.Ganguli, Dinesh Kumar H. Finite element analysis of free vibration of the delaminated composite plate with variable kinematic multilayered plate elements. Composites 2014; Part B, Vol. 66: pp.453-465.

[6] Alnefaie.K. Finite element modeling of composite plates with internal delamination. Composite Structures 2009; Vol.90: pp.2127.

[7] Yam L.H., Wei Z, Cheng, Wong W.O. Numerical analysis of multilayer composite plates with internal delamination. Computers and Structures 2004; Vol.82: pp.627-637.

[8] S. SANYASI NAIDU \& Ch. RATNAM, DELAMINATION IDENTIFICATION OF FRP COMPOSITES USING NORMALIZED MODAL CURVATURE, International Journal of Mechanical and Production Engineering Research and Development (IJMPERD), 2020, Vol. 10, pp. 645-656.

[9] N.T.Khiem, Toan.L.K. A novel method for crack detection in beam like structures by measurements of natural frequencies. Journal of sound and vibration 2014; Vol.333: pp.4084-4103.

[10] A. Ahmed. Elshafey, H.Marzouk., M.R. Haddara. Experimental Damage Identification Using Modified Mode Shape Difference. J.Marine Sci. Appl. 2011; Vol.10: pp. 150-155.

[11] Z.Jianhua, L.Zhang. Structural Damage Identification Based on the Modal Data Change I.J. Engineering and Manufacturing 2012; Vol.4; pp.59-66

[12] S Sanyasi Naidu, Ch Ratnam. Delamination Assessment of FRP Composite Plate Using Natural Frequencies. International Journal of Engineering and Advanced Technology 2019; Volume-9 Issue2:pp. $2249-8958$
[13] D.Garcia, R.Palazzetti., I. Trendafilova., C.Fiorini, A.Zucheli. Vibration based delamination diagnosis and modelling for composite laminated plates. Composite structures 2015; vol.130: pp. $155-162$

[14] A.K.Pandey, M.Biswas, M.M.Samman. Damage detection from changes in curvature mode shapes. Journal of Sound and Vibration 1991; vol. 145(2):, pp.321-332.

[15] L.W.Qiao, S.Hanagud. Curvature Mode Shape based Damage Assessment of Carbon/Epoxy Composite Beams. Journal of Intelligent Material Systems and Structures 2007; Vol.18: pp.189 209

[16] Q. Pizhong, Lu Khan L.W. , J.Wang. Curvature mode shape based damage detection in composite laminated plates. Composite Structures 2007; Vol.80: pp. 409-428.

[17] H.Hu, B.T. Wang, Cheng Lee, Su.J.Shiang. Damage detection of surface cracks in composite laminates using modal analysis and strain energy method. Composite Structures 2006; Vol.74 pp.399-405.

[18] W.Xu.,M.S.Cao, M.Radzienski., Xia. N.O.W, S.S.Wang Detecting multiple small sized damage in beam type structures by Teager energy of modal curvature shape. Journal of Vibroengineering 2015; Vol.17: pp.275-286.

[19] J.V.A.Santos, M.Mota.S.C.,Mota S.C.A, Pina.H.L.G. Development of a numerical model for the damage identification on composite plate structures. Composite Structures 2000; Vol.48: pp.59-65.

[20] M.C.Shekhar, R.Ganguli. Structural Damage Detection Using Modal Curvature and Fuzzy Logic. Structural Health Monitoring 2009; Vol.8: pp.267-282.

[21] Azmat Hussain, Saba Bashir, Saima Maqbool. DAMAGE DETECTION IN BRIDGES USING IMAGE PROCESSING. International Journal of Civil Engineering and Technology (IJCIET) 2016; Vol.7: pp. 215-225.

[22] Mohan N, Bhavani N,. Kasthuri K, R.A.Varun, Bhavya M Detection and Quantification of Road Surface Damage using Digital Image Processing Techniques. International Journal of Engineering Research \& Technology 2017; Vol.6: pp.185-188.

[23] Nhat-Duc Hoang. Image Processing-Based Recognition of Wall Defects Using Machine Learning Approaches and Steerable Filters. Computational Intelligence and Neuroscience 2018; Article ID 7913952 